\title{
Overview of the Evolution of the UK Kidney Allocation Schemes
}

\author{
Christopher J. E. Watson ${ }^{1} \cdot$ Rachel J. Johnson ${ }^{2} \cdot$ Lisa Mumford ${ }^{2}$
}

Published online: 12 March 2020

(C) The Author(s) 2020

\begin{abstract}
Purpose of Review Allocation of deceased donor kidneys for transplantation has evolved since the first utilitarian approach in 1989. This review looks at how the schemes have evolved over the ensuing three decades.

Recent Findings Four kidney offering schemes have been used in the last 30 years. Successive schemes have evolved from offering only one donor kidney for a nationally prioritised patient to offering both kidneys, from addressing only kidneys from donors after brain death (DBD) to offering kidneys from both DBD and circulatory death donors (DCD) and from prioritising purely on the basis of zero class 2 and minimising class 1 mismatches to a more relaxed approach for older donors and more difficult to match patients while introducing the concept of longevity matching.

Summary UK kidney offering schemes have evolved through a series of evidence-based analyses to try to optimally address the principles of utility and fairness in kidney offering.
\end{abstract}

Keywords Kidney transplantation $\cdot$ Kidney allocation

\section{Introduction}

Organ offering schemes in the UK have developed as a compromise between utility (optimising the outcomes for a particular kidney) and justice (fairness). Analyses of prospectively collected national data have identified donor and recipient combinations associated with better graft outcomes and prioritised offering for such combinations. At the same time, compromises had to be reached between local issues relating to organ recovery and serving the requirements of those who were sensitised or had rare tissue types. As the schemes have evolved, the differing and often conflicting priorities have been accommodated by utilising points scoring based systems, where points are used to weigh various donor and recipient characteristics in a potential donor-recipient match, such that every possible donor and recipient combination is

This article is part of the Topical Collection on OPTN Policy

Christopher J. E. Watson

cjew2@cam.ac.uk

1 Department of Surgery, University of Cambridge, Box 210, Addenbrookes Hospital, Cambridge, CB2 0QQ, UK

2 NHS Blood and Transplant, Bristol, UK assigned a score and the two recipients with the highest donor-recipient scores would be offered an organ. How much weighting was given to each criterion depended upon the opinion of a panel of experts, lay members and patient representatives, and the results were modelled before implementation to check that the predicted effects were as intended.

At the same time, there has been a requirement to allow recipients of other organs who also need a kidney at the same time to be accommodated, such as those awaiting a combined kidney and pancreas transplant. Suitable priority for such recipients was necessary to enable the UK national pancreas offering scheme to work effectively.

During the evolution of the schemes, donor identification and organ retrieval practices have changed. Renal centres used to attend all the donors in their regions and remove the kidneys, while liver teams would remove the liver. Over time the liver centres removed more and more donor kidneys while the regional renal centre did not attend the donor. In 2010 a national organ retrieval service was established to ensure that just one abdominal team and one cardiothoracic team attend each donor. At the same time, responsibility for donor identification changed from being the responsibility of regional transplant centres to being a national service. These changes had the effect of removing the sense of ownership from locally removed deceased donor kidneys and a greater acceptance of national sharing. 
In this article, we detail the evolution of UK kidney offering, from a scheme where one of the pair of kidneys from a donor was offered largely on utilitarian principles alone to one where equity of access and fairness combine with utilitarian priorities.

\section{Beneficial Matching: The 1989 Scheme}

In 1987 an analysis was performed of 2282 UK deceased donor kidneys transplanted between 1979 and 1984, a period before ciclosporin was widely used [1,2]. It showed a graft survival benefit for HLA-A, B, (Class I) and DR (Class II) 0-0-0 mismatched kidneys, with 1-0-0 and 0-1-0 being the next best combinations, followed by kidneys with two Class I or at least one Class II HLA mismatch. Gilks et al. had also shown the previous year that a pool of 5000 patients would allow an HLA A, B, DR compatible transplant in $28 \%$ of cases [3]. Following this work, the UK introduced an allocation scheme in 1989 whereby one kidney from a pair would be shared nationally, the other kept locally (Table 1). The shared kidney would be allocated first to a 0-0-0 mismatched recipient, or if there were none, then to either a 1-0-0 or 0-1-0 mismatched recipient, termed beneficial matches. Preference would be given to children or to a local recipient for a beneficial match. The other kidney would be kept locally to minimise ischaemic time and could be transplanted into the recipient of the centre's choice. In addition, sera from the $20 \%$ of patients who were sensitised to over $80 \%$ of donors was shared between centres to allow a cross-match to be performed if a suitable beneficially matched kidney became available.

At the time beneficial matching was introduced, transplant coordinators were employed by local centres and were involved in donor and recipient coordination. Retrieval was undertaken by the nearest transplant centre. Donor activity was more a product of local efforts and engagement than national policy. Beneficial matching made a utilitarian offer of one kidney, while at the same time not depriving the local centre of both the kidneys that they had retrieved. Nevertheless the scheme was not well received by everyone, with criticism that the outcomes of good donor kidneys were being prejudiced by the increased ischaemic time incurred in travelling around the country and that many centres were net losers in the scheme while others net beneficiaries, such that for a single centre, the benefits of so-called beneficial matching may be difficult to realise [4]. In addition there was an argument that the enhanced immunosuppression afforded by ciclosporin, when compared to that offered by the azathioprine/steroid combination that went before, overcame any effect of HLA mismatching [5], although both assertions were refuted by others $[6,7]$.

\section{Favourable Matching: The 1998 Scheme}

In 1996 the UK data were reviewed in light of concerns that factors other than HLA match were important to consider in any scheme. An analysis of 13,714 kidney transplants performed between 1986 and 1993 was undertaken [8]. This analysis showed that donor and recipient age, cause of death, recipient diabetes and HLA mismatches all significantly affected outcomes. Longer cold ischaemic times were also shown to be associated with poorer outcomes, but whether a kidney was kept locally or not did not affect outcomes when adjusted for other factors. The resultant scheme offered both kidneys for any 0-0-0 mismatches nationally, or the first of a pair for favourably matched recipients defined as being $0-1-0,1-0-0$ or 1-1-0 mismatched; allocation of the remaining kidney was left to the centre's own discretion. Those kidneys that were offered were prioritised for highly sensitised patients over nonsensitised and children over adults. A points system was used as a tie break to prioritise the other recipients, taking into account factors such as recipient age (prioritising younger adults), the difference in donor and recipient age, waiting time, sensitisation and the likelihood of receiving a favourably matched kidney (later termed matchability); it also included a transplant centre balance of exchange factor to try to minimise export deficits $[9,10]$.

The scheme was amended periodically. By prioritising patients with no HLA-DR mismatches, this and preceding schemes had inadvertently biased against DR homozygote patients who would have at least one HLA-DR mismatch with the majority of donors since the majority are heterozygous at HLA DR. Moreover, any DR homozygote donors would be compatible with any HLA DR heterozygote bearing the same HLA DR, irrespective of the recipient's other DR antigen; hence HLA-DR homozygote recipients would rarely be allocated a zero mismatch HLA-DR homozygous donor kidney, and thus they always waited longer for a kidney. In 2000 this bias was redressed by giving additional prioritisation for patients who were homozygous at the HLA-DR locus. Further modification in 2002 allowed patients of blood group B to access favourably matched blood group $\mathrm{O}$ donor kidneys, due to longer waiting times for blood group B patients compared to patients of other blood groups.

The scheme achieved many of its objectives. The proportion of HLA 0-0-0 mismatched kidneys rose from 7 to $16 \%$ for adults, and favourable grafts rose from 43 to $52 \%$. Children achieved matching comparable to that achieved in adults for the first time in the UK, with 9\% 0-0-0 mismatched and $55 \%$ favourably matched compared to $5 \%$ and $30 \%$, respectively, under the previous scheme. More highly sensitised patients were transplanted (50 per year compared to 18 in 1997). 
Table 1 Sharing schemes in the UK

\begin{tabular}{|c|c|c|c|}
\hline Scheme & Era & Number of kidneys shared & Prioritisation \\
\hline Beneficial matching & 1989-1998 & One & $\begin{array}{l}\text { Tier 1: } 000 \\
\text { (a) Local > national } \\
\text { (b) Highly sensitised over not highly sensitised } \\
\text { (c) Child > adult } \\
\text { Tier 2: } 100,010 \text { recipients } \\
\text { (a), (b) and (c) as above } \\
\text { Tier 3: Non-beneficially matched: Local allocation policy }\end{array}$ \\
\hline Favourable matching & $1998-2006$ & $\begin{array}{l}\text { One; both if there were } \\
\text { two } 000 \text { mismatches }\end{array}$ & $\begin{array}{l}\text { Tier 1: } 000 \\
\text { a) Highly sensitised }>\text { non-sensitised } \\
\text { b) Children }>\text { adults } \\
\text { c) HLA-DR homozygotes }>\text { HLA-DR heterozygotes } \\
\text { d) Local > national } \\
\text { Tier 2: } 100,010,110 \text { recipients } \\
\text { (a) to (d) as above } \\
\text { Tier 3: Non-favourably matched: Local allocation policy }\end{array}$ \\
\hline Equitable matching & 2006-2019 & Two & $\begin{array}{l}\text { Tier A: } 000 \text { mismatched paediatric patients: HSP/HLA-DR homozygote } \\
\text { Tier B: } 000 \text { mismatched paediatric: Non HSP/HLA-DR homozygote } \\
\text { Tier C: } 000 \text { mismatched adult HSP/HLA DR homozygote } \\
\text { Tier D: } 000 \text { mismatched adults (non HSP/homozygote); } \\
\text { HLA-A, B, DR 100, 010, } 110 \text { mismatched paediatric } \\
\text { Tier E: All others }\end{array}$ \\
\hline Longevity matching & 2019 on & Two & $\begin{array}{l}\text { Tier A: The } 10 \% \text { most difficult to match patients and any patients on } \\
\text { waiting list over } 7 \text { years } \\
\text { Tier B: Remaining patients, prioritised based on points score: } \\
\text { a) Donor and recipient risk index match } \\
\text { b) Waiting time } \\
\text { c) HLA mismatch/age } \\
\text { d) Local region > non-local region (of } 4 \text { national regions) }\end{array}$ \\
\hline
\end{tabular}

HSP Highly sensitised patient. Highly sensitised is defined as a calculated reaction frequency of $>85 \%$ against a pool of 10,000 donors

HLA Human leucocyte antigen

\section{Equitable Sharing of All Kidneys: The 2006 Scheme}

Placing emphasis on minimising HLA mismatches biased against offering kidneys to recipients who were homozygous at any HLA locus, particularly HLA-DR, but also was inequitable for patients of minority ethnic groups whose HLA types were not well represented in the donor pool [11]. The 2006 scheme arose out of a desire to improve access to a transplant for people of all ethnicities and tissue types, to achieve a fairer scheme acceptable to all patients. The scheme also recognised that the local centres were no longer retrieving kidneys, and therefore they did not feel the same degree of ownership of those kidneys, and so it was now able to offer both kidneys from each donor for national allocation.

The main aims of the scheme were to reduce variation in waiting times for a transplant while ensuring younger patients who would require more than one graft in their lifetime were allocated better matched kidneys, while not being so rigorous in the matching offered to older patients. In addition, younger patients were offered more priority beyond previously afforded paediatric priority when under 18 years of age.

There were two components to the 2006 scheme. The first was an alteration to how HLA mismatches were defined for the purposes of the matching scheme: rare HLA antigens, present in less than $2 \%$ of the population, were defaulted to more common specificities known to be associated with little serological cross reactivity, thus making it possible for those with rarer HLA types to be an apparent match (Table 2). The second was an analysis of the 1998 scheme, identifying areas of inequity and introducing solutions $[10,12]$. To achieve the goals identified above, a scheme was developed with 'Tiers' of priority, and the following criteria were given a weighting according to their perceived importance, as determined by the professional and patient members of the group who developed it. Weighting points were awarded for the following [13]:

- HLA mismatch and age: More points for HLA matches for younger patients.

- Waiting time: A point for every day on the waiting list.

- Difference between donor and recipient ages: To minimise difference.

- Location of donors: Dividing the country into 3 zones, with points if the donor is within the same zone in order to avoid long distance transfers, and thus minimising ischaemic time.

- HLA-B and -DR homozygous patients, to compensate for the focus on minimising DR and B mismatches when HLA matching is prioritised. 
Table 2 Defaulted HLA specificities to facilitate matching of rarer HLA types

\begin{tabular}{llc}
\hline Rare specificity & $\begin{array}{l}\text { Related specificity to } \\
\text { which rare specificity } \\
\text { was defaulted }\end{array}$ & $\begin{array}{l}\text { \% of donor pool } \\
\text { of defaulted specificity }\end{array}$ \\
\hline A36, A80 & A1 & 18 \\
A43 & A10 & 4 \\
B53 & B5 & 5 \\
B42, B73, B81 & B7 & 15 \\
B59 & B8 & 13 \\
B82, B83 & B12 & 18 \\
B46 & B15 & 7 \\
B67 & B22 & 2 \\
B47 & B27 & 5 \\
B70, B78 & B35 & 7 \\
B41, B48 & B40 & 7 \\
DR101, DR10 & DR1 & 10 \\
DR9 & DR4 & 20 \\
DR11, DR12 & DR5 & 8 \\
\hline
\end{tabular}

- Blood group: Blood group AB patients could receive A kidneys; well-matched blood group B patients could receive blood group $\mathrm{O}$ kidneys.

These weighting factors were used to prioritise within Tiers $\mathrm{C}$ to $\mathrm{E}$, while waiting time alone was used to prioritise in Tiers $\mathrm{A}$ and $\mathrm{B}$ (Table 1).

Patients awaiting multi-organ transplants including a kidney, such as a kidney and pancreas transplant, would be allocated one kidney provided that both kidneys had not first been allocated to patients in Tiers A and B [14*0].

The scheme was successful in reducing the number of long-waiting patients: After 3 years, the proportion of patients on the wait list who had been waiting more than 5 years fell from 17 to $8 \%$. Also, $12 \%$ of transplants involved defaulting of rare antigens, and there were more transplants for ethnic minority patients (who were over-represented on the transplant list): from $17 \%$ of all transplants previously to $20 \%$ under the 2006 scheme. For paediatric patients, the proportion of less well-matched grafts (i.e. not 000 or favourable matches) fell from $17 \%$ to $9 \%$, reducing chances of sensitisation that would make future transplants more difficult.

\section{Scheme: Longevity Matching}

The 2006 scheme achieved many of its goals but had several limitations. First, when it was developed, around $10 \%$ of kidneys were from DCD donors, an activity that was focused on a few centres. These centres invested time to develop local controlled DCD programmes, did the DCD retrievals themselves, and were rewarded by being able to allocate both kidneys to local patients using locally developed algorithms [15]. Following publication of data showing the good long-term outcomes of DCD kidneys [16], there was a change in UK practice with increasing utilisation such that DCD kidneys now comprise $40 \%$ of all deceased donor kidney transplants. This led to an interim scheme to allocate one of each pair of DCD kidneys to a national patient, the other being kept locally.

Another observation of the 2006 scheme was that around half of standard criteria DBD kidneys were declined by the centre to which they were offered, before being transplanted elsewhere. There may have been many reasons for this, such as the potential recipient being unfit or other donor issues (e.g. infection risk) making the kidney less than ideal, but often it was a perception that the potential recipient would get a better offer. Indeed, analysis of the 2006 scheme also confirmed that younger patients were more likely to have an older donor kidney turned down, while offers were less often turned down for an older patient. Moreover, younger patients were more likely to outlive their graft, while older recipients more commonly died with a functioning graft. While donor-recipient age matching was a factor in the scheme, there was evidence that something more effective was required, particularly as donor ages continued to increase. The analysis also showed that despite prioritisation for sensitised patients, they were still waiting significantly longer than non-sensitised patients and that often this long wait could be predicted from the time they were listed.

A new scheme was developed in 2019. Termed an offering scheme rather than an allocation scheme in recognition of the fact that the recipient centres and patients had the final say in accepting the offer, it attempted to address a number of the issues causing concern in respect of the 2006 scheme. First, both DBD and DCD kidneys were now included in the offering scheme. The scheme gives priority to sensitised patients from the outset, with the aim of bringing their waiting time down to something akin to that of non-sensitised patients, but at the expense of this, offers may be immunologically acceptable, but not favourable, HLA mismatches. It also introduced an element of longevity matching, to try to match the estimated life of the donor kidney to the estimated longevity of the recipient, using indices derived from donor and recipient factors shown to predict the likelihood of recipient death or graft loss. In addition, it afforded priority for minimising HLA mismatches in younger patients to improve outcomes, while reducing the breadth of sensitisation that might follow a failed graft, in a group of patients likely to need more than one transplant in their lifetimes. This scheme went live in September 2019 after a number of simulations to ensure predicted results met the initial objectives of the scheme. Time will tell whether it does actually achieve its aims.

\section{Conclusions}

Kidney offering schemes in the UK have evolved from a purely utilitarian approach involving only one DBD kidney 
being allocated on the basis of HLA mismatch minimisation to a scheme which offers both kidneys, with a focus on HLA matching and maximising longevity in younger recipients while relaxing HLA matching for sensitised patients to enable them to be transplanted sooner. These changes have been made possible by advances in immunosuppression facilitating better results in less well-matched grafts and the introduction of a national organ retrieval service removing local ownership of donor kidneys. At the same time, periods of 'local ownership' have been important first in developing kidney transplantation nationally and latterly in developing one of the biggest DCD kidney programmes in the world.

Acknowledgements The views expressed are those of the authors and not necessarily those of the NIHR, the Department of Health and Social Care or NHSBT.

Funding Information The research was funded by the National Institute for Health Research Blood and Transplant Research Unit (NIHR BTRU) in Organ Donation and Transplantation at the University of Cambridge in collaboration with the Newcastle University and in partnership with NHS Blood and Transplant (NHSBT). The University of Cambridge has received salary support in respect of CJEW from the NHS in the East of England through the Clinical Academic Reserve.

\section{Compliance with Ethical Standards}

Conflict of Interest The authors have no conflicts of interest to declare in respect of this paper.

Human and Animal Rights and Informed Consent This article is a literature review and contains no studies on animal or human subjects performed by any of the authors.

Open Access This article is licensed under a Creative Commons Attribution 4.0 International License, which permits use, sharing, adaptation, distribution and reproduction in any medium or format, as long as you give appropriate credit to the original author(s) and the source, provide a link to the Creative Commons licence, and indicate if changes were made. The images or other third party material in this article are included in the article's Creative Commons licence, unless indicated otherwise in a credit line to the material. If material is not included in the article's Creative Commons licence and your intended use is not permitted by statutory regulation or exceeds the permitted use, you will need to obtain permission directly from the copyright holder. To view a copy of this licence, visit http://creativecommons.org/licenses/by/4.0/.

\section{References}

Papers of particular interest, published recently, have been highlighted as:

- Of importance

•- Of major importance

1. Gilks WR, Gore SM, Bradley BA. Analyzing transplant survival data. Transplantation. 1986;42(1):46-9. https://doi.org/10.1097/ 00007890-198607000-00009.
2. Gilks WR, Bradley BA, Gore SM, Klouda PT. Substantial benefits of tissue matching in renal transplantation. Transplantation. 1987;43(5): 669-74. https://doi.org/10.1097/00007890-198705000-00013.

3. Gilks WR, Bradley BA, Gore SM. Beneficial HLA matching. Lancet. 1986;1(8479):509. https://doi.org/10.1016/s0140-6736(86)92975-2.

4. Salaman JR, Ross WB. Exchanging kidney transplants-is it worth it? Lancet. 1987;1(8548):1480-1. https://doi.org/10.1016/s01406736(87)92220-3.

5. Harris KR, Digard N, Gosling DC, Tate DG, Campbell MJ, Gardner B, et al. Azathioprine and cyclosporin: different tissue matching criteria needed? Lancet. 1985;2(8459):802-5. https:// doi.org/10.1016/s0140-6736(85)90795-0.

6. Gore SM, Gilks WR. Exchanging kidney transplants. Lancet. 1987;2(8557):507. https://doi.org/10.1016/s0140-6736(87)91810-1.

7. Cicciarelli J, Terasaki PI, Mickey MR. HLA matching and cyclosporin immunosuppression: a strong correlation. Lancet. 1986;1(8475):267. https://doi.org/10.1016/s0140-6736(86)90796-8.

8. Morris PJ, Johnson RJ, Fuggle SV, Belger MA, Briggs JD. Analysis of factors that affect outcome of primary cadaveric renal transplantation in the UK. HLA Task Force of the Kidney Advisory Group of the United Kingdom Transplant Support Service Authority (UKTSSA). Lancet. 1999;354(9185):1147-52. https://doi.org/10. 1016/s0140-6736(99)01104-6.

9. Fuggle SV, Johnson RJ, Rudge CJ, Forsythe JL. Human leukocyte antigen and the allocation of kidneys from cadaver donors in the United Kingdom. Transplantation. 2004;77(4):618-20. https://doi. org/10.1097/01.tp.0000103726.37649.ef.

10. Fuggle SV, Johnson RJ, Bradley JA, Rudge CJ. Kidney Advisory Group of NHSBT. Impact of the 1998 UK National Allocation Scheme for deceased heartbeating donor kidneys. Transplantation. 2010;89(4):372-8. https://doi.org/10.1097/TP.0b013e3181c90270.

11. Rudge C, Johnson RJ, Fuggle SV, Forsythe JL. Kidney and pancreas advisory group of NHSBT. Renal transplantation in the United Kingdom for patients from ethnic minorities. Transplantation. 2007;83(9):1169-73. https://doi.org/10.1097/01.tp.0000259934.06233. ba.

12. Johnson RJ, Fuggle SV, O'Neill J, Start S, Bradley JA, Forsythe JL, et al. Factors influencing outcome after deceased heart beating donor kidney transplantation in the United Kingdom: an evidence base for a new national kidney allocation policy. Transplantation. 2010;89(4): 379-86. https://doi.org/10.1097/TP.0b013e3181c90287.

13. Johnson RJ, Fuggle SV, Mumford L, Bradley JA, Forsythe JL, Rudge CJ, et al. A new UK 2006 National Kidney Allocation Scheme for deceased heart-beating donor kidneys. Transplantation. 2010;89(4): 387-94. https://doi.org/10.1097/TP.0b013e3181c9029d.

14.• Hudson A, Bradbury L, Johnson R, Fuggle SV, Shaw JA, Casey JJ, et al. The UK Pancreas Allocation Scheme for Whole Organ and Islet Transplantation. Am J Transplant. 2015;15(9):2443-55. https://doi.org/ 10.1111/ajt.13284 This paper shows how the UK pancreas allocation scheme was developed, and how well the simulations predicted what actually happened. Similar simulations have been undertaken in developing all the iterations of the UK kidney offering schemes during its evolution.

15. Laugharne MJ, Clarke E, Younie ME, Johnson RJ, Rudge CJ, Pentlow $\mathrm{BD}$, et al. A novel scheme for graft allocation in non-heart beating donor renal transplantation. Transplantation. 2008;85(11):1663-7. https://doi.org/10.1097/TP.0b013e318172cab2.

16. Summers DM, Johnson RJ, Allen J, Fuggle SV, Collett D, Watson $\mathrm{CJ}$, et al. Analysis of factors that affect outcome after transplantation of kidneys donated after cardiac death in the UK: a cohort study. Lancet. 2010;376(9749):1303-11. https://doi.org/10.1016/ S0140-6736(10)60827-6.

Publisher's Note Springer Nature remains neutral with regard to jurisdictional claims in published maps and institutional affiliations. 